\title{
Relationships between nasal potential difference and respiratory function in adults with cystic fibrosis
}

\author{
I. Fajac*, D. Hubert**, T. Bienvenu***, B. Richaud-Thiriez**, R. Matran*, J-C. Kaplan***, \\ J. Dall'Ava-Santucci*, D.J. Dusser**
}

Relationships between nasal potential difference and respiratory function in adults with cystic fibrosis. I. Fajac, D. Hubert, T. Bienvenu, B. Richaud-Thiriez, R. Matran, J-C. Kaplan, J. Dall'Ava-Santucci, D.J. Dusser. OERS Journals Ltd 1998.

ABSTRACT: This study investigated the relations between nasal transepithelial electric potential difference (PD) and the phenotype and genotype of cystic fibrosis (CF) adult patients.

Basal nasal PD was measured in 95 adult CF patients who were classified into three groups of nasal PD (expressed as absolute values) according to the 10th and the 90th percentiles (28.3 and $49.2 \mathrm{mV}$, respectively), which defined group 1 (nasal PD $\partial 28.3$ $\mathrm{mV}$ ), group 2 (nasal PD 28.3-49.2 mV) and group 3 (nasal PD S49.2 mV).

Patients from group 1 had a higher forced vital capacity (FVC) than patients from groups 2 and $3(76.5 \pm 22.4$ versus $57.4 \pm 21.2$ and $55.7 \pm 21.1 \%$ predicted, respectively, $p<0.05)$ and a higher forced expiratory volume in one second (FEV1) $(69.3 \pm 24.0$ versus $\mathbf{4 2 . 5} \pm 22.4$ and $42.2 \pm 21.4 \%$ pred, respectively, $p<0.01$ ). Among patients with severe mutations ( $\triangle$ F508 homozygotes, or one $\Delta$ F508 mutation plus another "severe" mutation, or two "severe" mutations), patients from group 1 had a higher FVC, FEV1 and arterial oxygen tension than patients from groups 2 and 3 ( $p<0.05$ for each comparison).

The results show that in adult cystic fibrosis patients a normal basal nasal potential difference is related to milder respiratory disease, irrespective of the severity of the genotype.

Eur Respir J 1998; 12: 1295-1300.

Cystic fibrosis (CF) is the most common lethal autosomal recessive disorder in the Caucasian population. It is associated with chronic airway disease which leads to an early death. The respiratory disease reflects mutations in the $\mathrm{CF}$ gene which codes for a protein, the cystic fibrosis transmembrane conductance regulator (CFTR) [1]. More than 500 different CF mutations have been described [2]. The association of two different mutations in compound heterozygotes with $\mathrm{CF}$ is responsible for a large heterogeneity of genotypes and for a broad spectrum of CFTR dysfunction levels. CFTR, which is present in the epithelium of the respiratory tract, functions as a cyclic adenosine monophosphate (cAMP)-regulated chloride channel and as a regulator of other channels [3]. Respiratory epithelia of patients with $\mathrm{CF}$ exhibit abnormal chloride and sodium transport across the apical surface of the cell [4]. This abnormal ionic transport generates an increased negative transepithelial electric potential difference (PD) that can be measured in vivo in the nasal epithelium using a method developed by KNowles et al. [5, 6]. Nasal PD meas-urement has been proposed as a diagnostic tool in CF [6, 7].

Relationships between the structure of the CFTR protein and its function have been described which, to some extent, allow the prediction of the severity of CFTR dysfunction from the type of $\mathrm{CF}$ mutation, and the possible consequences for severity of the disease [8]. As nasal PD reflects ionic nasal transepithelial transport, including CFTR Cl- channel transport, a relationship between nasal $\mathrm{PD}, \mathrm{CF}$ genotype and respiratory function might exist.
Depts of *Respiratory Physiology, **Respiratory Medicine and ***Genetic Biochemistry, Cochin Hospital, René Descartes University, Paris, France.

Correspondence: I. Fajac

Laboratoire de Physiologie Respiratoire

UFR Cochin Port-Royal

24, rue du Faubourg Saint-Jacques

75014 Paris

France

Fax: 33144412333

Keywords: Cystic fibrosis nasal potential difference

Received: March 91998

Accepted after revision August 81998
ALton et al. [7] have reported an inverse correlation between nasal PD expressed as absolute values and respiratory function. This finding was not confirmed in a recent study by Hofmann et al. [9]. Several studies have shown no clear relationship between CF genotype and nasal PD [10, 11]. However, $\mathrm{H}_{0}$ et al. [12] have found a relationship between mutations leading to the presence of an apical membrane CFTR protein and residual chloride secretion assessed by nasal PD following pharmacological stimulation. They found better respiratory function in those $\mathrm{CF}$ patients with the greater ability to secrete chloride in response to chloride secretagogues [12]. However, studying the ability of airway epithelium to secrete chloride upon pharmacological stimulation does not necessarily reflect the actual ionic transport across the epithelium that exists in basal conditions in vivo. It is also rather difficult to measure nasal PD under pharmacological stimulation as a routine procedure in a sample population.

The aim of this study was to investigate the relationships between basal nasal PD and the phenotype and genotype in adult $\mathrm{CF}$ patients. Ninety-five adult CF patients were classified into three groups of nasal PD according to the 10th and the 90th percentiles of the whole group PD distribution. The study examined, in the group of $\mathrm{CF}$ patients as a whole and in different groups of CF genotype, whether there was any difference between the three groups of nasal PD in terms of the phenotype of the disease related, in particular, to pulmonary involvement. 


\section{Patients and methods}

\section{Patients}

Ninety-five adult patients with $\mathrm{CF}$ were included in this prospective study (56 males and 39 females; mean age \pm SD $27 \pm 7$ yrs). All regularly attended the adult CF centre at Cochin Hospital, Paris (France), between January 1, 1995, and June 30, 1996. All had bronchiectasis confirmed by computed tomography (CT) scan. Diagnosis was confirmed by two abnormal sweat chloride concentration measurements (Š70 mmol. $\mathrm{L}^{-1}$ ) in at least $100 \mathrm{mg}$ of sweat collected by pilocarpine iontophoresis and/or the identification of two mutations in the CFTR gene. Only three patients had a normal sweat test: one was homozygotic for the $\Delta \mathrm{F} 508$ mutation and two patients were compound heterozygotic for the G542X and 3849+10 kb cytosine (C) $\rightarrow$ thymine (T) mutations and for the R1070Q and D1152H mutations, respectively.

\section{Measurement of nasal potential difference}

Nasal PD was measured by a technician who was blinded to the results of pulmonary function tests. No patient was studied within 4 weeks of acute infectious rhinitis. The technique used has been described previously [13]. In brief, the reference bridge was made of polyethylene tubing (1 mm i.d., Vygon, Ecouen, France) filled with Ringer's solution and taped to the skin such that the solution dripped slowly onto a scarification on the anterior face of the forearm. The exploring electrode consisted of a Foley catheter (Baxter, Maurepas, France) with lateral holes close to the tip. It was perfused with Ringer's solution by a constant-flow $\left(0.1 \mathrm{~mL} \cdot \mathrm{min}^{-1}\right)$ infusor (Vial Medical, Paris, France). Both branches of the bridge were connected through half-cell calomel electrodes (Radiometer, Copenhagen, Denmark) to a high-impedance millivoltmeter.

Before each nasal PD measurement, bridge conductivity was verified by preliminary measurements. Under short-circuit conditions, zero $\mathrm{mV}$ was obtained when the reference electrode was in contact with the exploring electrode. Then, the skin PD of the forearm was measured with the exploring electrode and these measurements produced a potential between -30 and $-60 \mathrm{mV}$.

The exploring electrode was advanced very slowly through the inferior meatus under the inferior turbinate, one lateral hole directed towards the nasal septum, until a maximal and stable PD was obtained, usually $3-4 \mathrm{~cm}$ from the anterior tip of the turbinate. It was verified by very slow electrode rotation that this value was maximal.

In 31 patients, measurements were made on up to three occasions separated by at least a few months and at most 3 yrs.

Values in normal subjects in our laboratory were established in 1992 and again in 1996. Similar mean \pm SD values were found on both occasions: $20.5 \pm 5.9 \mathrm{mV}(\mathrm{n}=40)$.

\section{Clinical assessment}

Data concerning clinical presentation included age, symptoms at diagnosis and history of meconium ileus. Sweat chloride concentrations were recorded.
Pancreatic status was determined from the fat content in stool samples collected over 3 days: patients showing normal results (faecal fat $<5 \mathrm{~g} \cdot$ day $^{-1}$ ) and currently not treated by pancreatic enzyme replacement were defined as pancreatic sufficient and the others as pancreatic insufficient. Body weight was expressed as a percentage of ideal weight for their height.

Lung function tests were performed in all patients while their disease was stable. A spirometer (Autospiro AS500; Minato, Osaka, Japan) was used to record the forced expiratory volume in one second (FEV1) and forced vital capacity (FVC). Technicians were blinded to the nasal PD results. Because the study population comprised patients of different ages, the decline in their pulmonary function was evaluated in relation to age. Therefore, an estimate was made of the percentage mean annual loss in FVC and FEV 1 , defined as (100 - \% pred FVC)/age and (100 - \% pred $\mathrm{FEV} 1) /$ age, respectively. Arterial oxygen tension $\left(\mathrm{Pa}, \mathrm{O}_{2}\right)$ and arterial carbon dioxide tension $\left(\mathrm{Pa}_{\mathrm{a}} \mathrm{CO}_{2}\right)$ were measured at rest.

Patients whose sputum gave positive cultures of $\mathrm{Pseu}$ domonas aeruginosa for at least 6 months were considered to be colonized with this micro-organism. The number of $i$.v. antibiotic courses per year and the number of days of $i . v$. antibiotics per year were recorded.

Finally, information was obtained on a history of pneumothorax, nasal polyps, hepatic cirrhosis, gallstones, diabetes mellitus, joint pains and pregnancy.

\section{Deoxyribonucleic acid analysis and classification of mutations}

Peripheral blood samples were collected and genomic deoxyribonucleic acid (DNA) was extracted by standard methods. All 27 exons of the CFTR gene and the surrounding intron sequences were analysed by denaturing gradient gel electrophoresis, as described previously [14, 15]. Polymerase chain reaction (PCR) products that displayed an altered behaviour in the gel were subsequently sequenced [16]. The intron mutations $3849+10 \mathrm{~kb} \mathrm{C} \rightarrow \mathrm{T}$ and $1811+1.6 \mathrm{~kb}$ adenine $(\mathrm{A}) \rightarrow$ guanine $(\mathrm{G})$ were screened separately, according to the protocols of Highsmith et al. [17] and CHLLòn et al. [18].

Using the approach for the classification of CFTR mutations proposed by WeLSH and SMITH [8] and as described previously [19], the patients were classified into four genotype groups according to the probable effect of their mutations on CFTR function, regardless of clinical features. Genotype group A included $\Delta \mathrm{F} 508$ homozygotic patients, group B included patients with no CFTR production or expected nonfunctional CFTR, group C included patients with partly functional CFTR, with at least one "mild" mutation and group D comprised patients with only one "severe" mutation or no identified mutation.

\section{Statistical analysis}

Nasal PD were always negative with respect to the reference bridge and were expressed as absolute values. Since considerable differences were occasionally recorded between the two nostrils, nasal PD was expressed for each patient as the highest value of the two nostrils [9]. Values of FVC and FEV1 were expressed as percentages of predicted values (\% pred). Group data were expressed as the 
median and range for age at diagnosis, the number of antibiotic courses and the number of days of antibiotics, since normal distribution of these variables cannot be demonstrated. All other variables were expressed as mean \pm SD. Data on nasal PD and quantitative data on clinical assessment were subjected to regression analysis. However, since the correlation between nasal PD and lung function tests was weak and the relation between these variables is probably not linear, this relation was analysed further after classification of the patients into three groups of nasal PD according to the 10th and the 90th percentiles, which corresponded to 28.3 and $49.2 \mathrm{mV}$, respectively. Group 1 included patients with nasal PD less or equal to the 10th percentile; group 2, patients with nasal PD between the 10th and the 90th percentiles and group 3 patients with nasal PD higher or equal to the 90th percentile. Comparisons between groups of nasal PD were made using oneway analysis of variance (ANOVA) or the Kruskal-Wallis test for parametric and nonparametric variables, respectively. Comparisons of frequency were made using the Chi-squared method. Values of pð0.05 were considered to indicate statistical significance.

\section{Results}

The mean \pm SD nasal PD was $38.0 \pm 8.2 \mathrm{mV}$ (range: $20.6-$ $62.5 \mathrm{mV}$ ) in the $95 \mathrm{CF}$ adult patients as a group. Values in normal subjects in our laboratory are $20.5 \pm 5.9 \mathrm{mV}(\mathrm{n}=$ 40 ). For the $31 \mathrm{CF}$ patients who had several nasal PD measurements, the mean of the differences between the first and the second measurements in a subject was $2.7 \pm 1.5$ $\mathrm{mV}$ and there was no difference between the first and the second measurements $(37.9 \pm 8.3$ and $36.3 \pm 9.7 \mathrm{mV}$, respectively, $\mathrm{p}>0.05$ ). Nasal PD in a given patient were consistently found to correspond to the same percentile group. This was also true for the six patients with nasal polyps and the four patients of group 1 in whom several nasal PD measurements were made over periods from several months to 3 yrs (data not shown).

\section{Clinical characteristics of the patients and basal nasal potential difference}

Clinical characteristics at the time of diagnosis. There were no significant differences among the three groups in terms of clinical characteristics at the time of diagnosis (table 1): mean age attained, age at diagnosis, symptoms at the time of diagnosis and sweat chloride concentrations were not different between the three groups.

Pancreatic and nutritional status. Similarly, there were no significant differences in pancreatic and nutritional status among the three groups of nasal PD (table 1). The numbers of patients with pancreatic insufficiency or diabetes were not different between the three groups. Similarly, no difference appeared for the nutritional status estimated by the percentage of predicted weight.

Pulmonary status. Nasal PD was related inversely to FVC $(\mathrm{r}=0.21, \mathrm{p}<0.05)$ and FEV1 $(\mathrm{r}=0.22, \mathrm{p}<0.05) . \mathrm{FVC}$ and FEV1 were significantly higher in patients from group 1 than in patients from groups 2 and $3(\mathrm{p}<0.05$ and $\mathrm{p}<0.01$,
Table 1. - Clinical and genotype data in the three groups of basal nasal potential difference, excluding respiratory data

\begin{tabular}{lccc}
\hline Variable & $\begin{array}{c}\text { Group 1 } \\
(\mathrm{n}=10)\end{array}$ & $\begin{array}{c}\text { Group 2 } \\
(\mathrm{n}=75)\end{array}$ & $\begin{array}{c}\text { Group 3 } \\
(\mathrm{n}=10)\end{array}$ \\
\hline Age yrs & $24(18-38)$ & $25(17-47)$ & $26(19-37)$ \\
Male sex n & 4 & 44 & 8 \\
Age at diagnosis yrs & $7(0.38)$ & $3(0-45)$ & $1(0-34)$ \\
Sweat Cl- mmol-L-1 & $108 \pm 26$ & $119 \pm 24$ & $122 \pm 14$ \\
Weight \% pred & $86.5 \pm 11.0$ & $84.1 \pm 10.3$ & $80.2 \pm 8.5$ \\
Symptoms at diagnosis & & & \\
$\quad$ Respiratory n & 3 & 42 & 5 \\
$\quad$ Digestive n & 7 & 41 & 5 \\
Meconium ileus n & 2 & 6 & 1 \\
Pancreatic & 8 & 57 & 10 \\
insufficiency n & & & \\
Diabetes n & 1 & 9 & 0 \\
Hepatic cirrhosis n & 1 & 8 & 0 \\
Gallstones n & 5 & 13 & 1 \\
Nasal polyps n & 3 & 22 & 4 \\
Joint pains n & 2 & 21 & 0 \\
Pregnancy n & 1 & 9 & 0 \\
Genotype & & & \\
$\quad$ Group A n & 6 & 30 & 6 \\
Group B n & 2 & 15 & 3 \\
Group C n & 1 & 14 & 1 \\
Group D n & 1 & 16 & 0 \\
\hline Resuls are expressed & & & \\
\hline
\end{tabular}

Results are expressed as median and range in parentheses, as mean \pm SD or as absolute value. Genotype group A included $\Delta \mathrm{F} 508$ homozygote patients, group $\mathrm{B}$ included patients with two "severe" mutations other than two $\Delta \mathrm{F} 508$ mutations, group $\mathrm{C}$ included patients with at least one "mild" mutation and group D included patients with only one "severe" mutation or no identified mutation.

respectively) (table 2). The estimated mean annual loss in FEV 1 was significantly less in group 1 than in groups 2 and $3(\mathrm{p}<0.05)$. Individual characteristics of the patients from group 1 are summarized in table 3 .

No significant difference was observed between the three groups in terms of the number of patients colonized with $P$. aeruginosa and the number of courses and days of i.v. antibiotics per year.

Other clinical data. No difference was observed between the three groups for history of nasal polyps, frequency of hepatic cirrhosis, gallstones, joint pains, successful pregnancies in females (table 1) or frequency of pneumothorax (table 2).

\section{Genotype study and basal nasal potential difference}

There was no significant difference in genotype distribution between the three groups of nasal PD (table 1). However, in genotype groups A and B, which correspond to the "severe" mutations in the genotype classification ( $\Delta$ F508 homozygotes, or one $\Delta \mathrm{F} 508$ mutation and one "severe" mutation, or two "severe" mutations), respiratory function was less impaired in patients of group 1 than in patients of groups 2 and 3 (table 4). FVC and FEV1 were higher in group 1 than in groups 2 and 3 ( $p<0.01$ and $\mathrm{p}<0.001$, respectively). The estimated mean annual loss in FVC and in FEV1 was lower in group 1 than in groups 2 and 3 ( $\mathrm{p}<0.01$ and $\mathrm{p}<0.001$, respectively). $P \mathrm{a}, \mathrm{O}_{2}$ was higher in group 1 than in groups 2 and $3(\mathrm{p}<0.05)$. 
Table 2. - Comparison of pulmonary data between the three groups of basal nasal potential difference

\begin{tabular}{|c|c|c|c|c|}
\hline Variable & $\begin{array}{c}\text { Group 1 } \\
(\mathrm{n}=10)\end{array}$ & $\begin{array}{c}\text { Group } 2 \\
(n=75)\end{array}$ & $\begin{array}{c}\text { Group } 3 \\
(\mathrm{n}=10)\end{array}$ & $\mathrm{p}$-value \\
\hline FVC \% pred & $76.5 \pm 22.4$ & $57.4 \pm 21.2$ & $55.7 \pm 21.1$ & $<0.05$ \\
\hline $\mathrm{FEV}_{1} \%$ pred & $69.3 \pm 24.0$ & $42.5 \pm 22.4$ & $42.4 \pm 21.4$ & $<0.01$ \\
\hline Est. annual loss in FVC \% & $1.0 \pm 0.9$ & $1.7 \pm 0.9$ & $1.7 \pm 0.8$ & Ns \\
\hline Est. annual loss in FEV1 \% & $1.3 \pm 1.0$ & $2.3 \pm 1.0$ & $2.2 \pm 0.8$ & $<0.05$ \\
\hline$P \mathrm{a}, \mathrm{O}_{2} \mathrm{mmHg}$ & $76.4 \pm 9.0$ & $69.3 \pm 11.4$ & $68.8 \pm 7.7$ & NS \\
\hline $\mathrm{Pa}_{\mathrm{a}, \mathrm{CO}_{2}} \mathrm{mmHg}$ & $37.6 \pm 4.3$ & $40.5 \pm 5.3$ & $40.4 \pm 4.9$ & NS \\
\hline Pseudomonas aeruginosa colonization $\mathrm{n}$ & 5 & 62 & 9 & NS \\
\hline Courses of $i . v$. antibiotics $\mathrm{n} \cdot \mathrm{yr}^{-1}$ & $1(0-3)$ & $3(0-12)$ & $2(0-6)$ & Ns \\
\hline Days of $i . v$. antibiotics days $\cdot \mathrm{yr}^{-1}$ & $15(0-63)$ & $37(0-365)$ & $28(0-168)$ & NS \\
\hline Pneumothorax n & 2 & 9 & 0 & as \\
\hline
\end{tabular}

Results are expressed as median and range in parentheses, as mean \pm SD or as absolute value. FVC: forced vital capacity; FEV1: forced expiratory volume in one second; Est.: estimated; $\mathrm{Pa}, \mathrm{O}_{2}$ : arterial oxygen tension; $P_{\mathrm{a}, \mathrm{CO}_{2}}$ arterial carbon dioxide tension. The $\mathrm{p}$-value is that for comparison of all groups $(1 \mathrm{mmHg}=0.133 \mathrm{kPa}$. $)$

\section{Discussion}

This study has shown that in adult CF patients with normal basal nasal PD, respiratory function was less impaired than in CF patients with higher nasal PD. Moreover, among CF patients with two "severe" mutations, a similar relationship between nasal PD and respiratory function was found: in patients with normal nasal PD, respiratory function was less impaired than in patients with higher nasal PD.

Ten patients had a nasal PD $228.3 \mathrm{mV}$, which is a normal value for our laboratory. However, the diagnosis of $\mathrm{CF}$ was definite in all patients. They all had symptomatic bronchiectasis and the diagnosis of CF was based on abnormal sweat chloride concentrations and/or the identification of two mutations in the CFTR gene. However, it is known that some overlap in baseline nasal PD may exist between CF patients and normal subjects [20] and that the sensitivity of this technique is usually around 90\% [9]. Inadequate measurements of nasal PD are unlikely to explain these results, as when several measurements separated at least by several months were performed in the same subject, the classification of the subject among the three groups of nasal PD did not change. Nasal PD can be lowered by nonspecific tissue damage at the time of an acute upper respiratory infection [21]. However, all nasal PD measurements took place at least 4 weeks after the end of symptomatic rhinitis. It has been suggested that the epi- thelial lining of polyps might produce a low nasal PD [7]. However, this is not supported by in vitro studies which showed that in normal subjects the epithelia of nasal turbinates and of nasal polyps have similar PD, whereas the nasal PD of polyp epithelia from $\mathrm{CF}$ subjects is raised compared with normal turbinates [22]. In the present study, patients with nasal polyps appeared in all three groups of nasal PD and there was no difference in the history of nasal polyps between the group. Furthermore, repeated measurements of basal nasal PD in patients with nasal polyps were found to be constantly within the same range of nasal PD.

The main finding of this study is that patients from group 1 with normal basal nasal PD had a higher FEV1 and FVC and a slower decline in pulmonary function, estimated by the mean annual loss in FEV1, than did the two other groups with higher nasal PD. Very few studies have evaluated the relationship between basal nasal PD and disease severity in CF patients. In a recent study in-cluding $34 \mathrm{CF}$ patients, no correlation was found between nasal $\mathrm{PD}$ and lung function tests [9]. However, in a cohort of 53 patients, ALTON et al. [7] reported that disease severity, as measured by FEV1 and FVC, was inversely correlated with nasal PD. In another recent study, Ho et al. [12] measured nasal PD in $22 \mathrm{CF}$ patients following pharmacological stimulation and classified their patients according to their ability to secrete chloride in response to chloride secretagogues. They found a higher FEV1 in the "high"

Table 3. - Individual characteristics of patients with normal nasal potential difference (group 1)

\begin{tabular}{|c|c|c|c|c|c|c|c|c|c|}
\hline $\begin{array}{l}\text { Subject } \\
\text { No. }\end{array}$ & $\begin{array}{l}\text { Age } \\
\text { yrs }\end{array}$ & Sex & $\begin{array}{l}\text { Sweat } \mathrm{Cl}^{-} \\
\mathrm{mmol} \cdot \mathrm{L}^{-1}\end{array}$ & $\begin{array}{c}\text { Nasal PD } \\
\text { mV }\end{array}$ & Genotype & $\begin{array}{l}\mathrm{FVC} \\
\% \text { pred }\end{array}$ & $\begin{array}{l}\text { FEV1 } \\
\% \text { pred }\end{array}$ & $\begin{array}{c}\mathrm{Pa}, \mathrm{O}_{2} \\
\mathrm{mmHg}\end{array}$ & $\begin{array}{l}{\mathrm{Pa}, \mathrm{CO}_{2}} \\
\mathrm{mmHg}\end{array}$ \\
\hline 1 & 24 & $\mathrm{M}$ & - & 20.6 & $\Delta \mathrm{F} 508 / \Delta \mathrm{F} 508$ & 64 & 62 & 82 & 40 \\
\hline 2 & 38 & $\mathrm{~F}$ & 106 & 23.2 & ?/? & 96 & 87 & - & - \\
\hline 3 & 29 & $\mathrm{~F}$ & 100 & 23.5 & $\Delta \mathrm{F} 508 / \mathrm{W} 846 \mathrm{X}$ & 101 & 95 & 82 & 38 \\
\hline 4 & 19 & M & 116 & 25.0 & $\Delta \mathrm{F} 508 / \Delta \mathrm{F} 508$ & 87 & 84 & 84 & 36 \\
\hline 5 & 20 & M & 120 & 25.5 & $\Delta \mathrm{F} 508 / \Delta \mathrm{F} 508$ & 75 & 63 & 77 & 41 \\
\hline 6 & 18 & $\mathrm{~F}$ & 132 & 27.5 & $\Delta \mathrm{I} 507 / \mathrm{Q} 980 \mathrm{X}$ & 103 & 103 & 72 & 38 \\
\hline 7 & 26 & $\mathrm{~F}$ & 140 & 27.8 & $\Delta \mathrm{F} 508 / \Delta \mathrm{F} 508$ & 86 & 72 & 91 & 31 \\
\hline 8 & 20 & $\mathrm{M}$ & 60 & 28.0 & $\Delta \mathrm{F} 508 / \Delta \mathrm{F} 508$ & 65 & 59 & 69 & 45 \\
\hline 9 & 24 & $\mathrm{~F}$ & 123 & 28.1 & $\Delta \mathrm{F} 508 / \Delta \mathrm{F} 508$ & 33 & 25 & 67 & 37 \\
\hline 10 & 26 & $\mathrm{~F}$ & 79 & 28.3 & R1070Q/? & 55 & 43 & 64 & 32 \\
\hline
\end{tabular}

Cystic fibrosis was diagnosed in patient No. 1 at birth and meconium ileus and abnormal sweat chloride concentrations were found in childhood. Patient No. 2, who had had high sweat chloride concentrations several times refused blood gas analysis. Patient No. 10, who has had respiratory symptoms since the age of $13 \mathrm{yrs}$, was diagnosed at $20 \mathrm{yrs}$ on abnormal sweat chloride concentrations and has been colonized by Pseudomonas aeruginosa for 2 yrs. M: male; F: female; PD: potential difference; see table 2 for other abbreviations. $(1 \mathrm{mmHg}=0.133 \mathrm{kPa}$.) 
Table 4. - Comparison of pulmonary data between the three groups of basal nasal potential difference in the patients with a severe genotype (groups $A$ and $B$ )

\begin{tabular}{lcccc}
\hline Variable & $\begin{array}{c}\text { Group 1 } \\
(\mathrm{n}=8)\end{array}$ & $\begin{array}{c}\text { Group 2 } \\
(\mathrm{n}=45)\end{array}$ & $\begin{array}{c}\text { Group 3 } \\
(\mathrm{n}=9)\end{array}$ & p-value \\
\hline FVC \% pred & $76.7 \pm 22.9$ & $52.8 \pm 17.6$ & $58.0 \pm 21.0$ & $<0.01$ \\
FEV1 \% pred & $70.3 \pm 24.4$ & $37.4 \pm 18.8$ & $43.3 \pm 22.3$ & $<0.001$ \\
Est. annual loss in FVC \% & $1.0 \pm 1.0$ & $2.0 \pm 0.8$ & $1.6 \pm 0.8$ & $<0.01$ \\
Est. annual loss in FEV1 \% & $1.3 \pm 1.1$ & $2.6 \pm 0.8$ & $2.2 \pm 0.9$ & $<0.001$ \\
$\mathrm{~Pa}_{2} \mathrm{O}_{2} \mathrm{mmHg}$ & $78.0 \pm 8.2$ & $66.6 \pm 10.6$ & $68.1 \pm 7.8$ & $<0.05$ \\
$\mathrm{~Pa}_{\mathrm{a}} \mathrm{CO}_{2} \mathrm{mmHg}$ & $38.2 \pm 4.1$ & $41.7 \pm 5.6$ & $40.8 \pm 5.1$ & NS \\
\hline
\end{tabular}

Results are expressed as mean \pm SD. See table 2 for abbreviations. ( $1 \mathrm{mmHg}=0.133 \mathrm{kPa}$.)

chloride secretors. Basal nasal PO can be taken as an estimate of the rate of $\mathrm{Na}^{+}$, transport which is regulated by CFTR and is one of the main ion transport abnormalities in CF lung disease [20]. The present results show that $\mathrm{CF}$ patients with a normal nasal PD are likely to have better respiratory function than those with abnormal nasal PD. The relationship that the authors and others [12] have found between respiratory function and nasal PD in CF should be compared with the finding of a relationship between residual chloride secretion measured in rectal biopsies in CF patients and preserved pancreatic function [23].

The relationship between normal nasal PD and mildly impaired respiratory function suggests that, in these patients, either CFTR is partly functional or CFTR deficiency is compensated by other factors that influence ion transport across the epithelium. The hypothesis of a partly functional CFTR is not supported by the fact that, even in patients with "severe" mutations, the same relationship was found between normal nasal PD and milder impairment of respiratory function. In addition, no difference was found in genotype distribution among the three groups of nasal PD. Hence, "mild" mutations (groups C and D) were no more frequent in group 1 than in the other groups. Although it would be tempting to predict the airway bioelectrical properties from the $\mathrm{CF}$ mutations, several studies including the present one have not confirmed this hypothesis. In five $\mathrm{CF}$ patients carrying the $\mathrm{A} 455 \mathrm{E}$ mutation associated with mild pulmonary disease, severe defects in airway bioelectrical properties were found [10]. In 25 patients carrying the $\Delta \mathrm{F} 508$ mutation, no difference was found in nasal PD between a group of $\Delta \mathrm{F} 508$ homozygotes and groups of compound heterozygotes for $\Delta \mathrm{F} 508$ [11]. In a recent study, $22 \mathrm{CF}$ patients were divided into two groups of genotype according to the expected apical membrane localization of the CFTR protein. The group in whom apical CFTR was present showed a greater capacity to secrete chloride, as measured by nasal PD following chloride secretagogues [12]. However, "high" chloride secretors could be found even in some patients with a $\Delta$ F508 homozygous genotype, in whom most of the CFTR protein does not reach the apical membrane. In the present study, six patients in group 1 with normal nasal PD had a $\Delta$ F508 homozygous genotype, in which CFTR function is thought to be highly impaired. Similarly, in the study conducted by VEEZE et al. [23] on chloride secretion in rectal biopsies, among the 21 patients in whom residual chloride secretion was found, four were homozygous for the $\Delta$ F508 mutation. Taken together, these results reinforce the idea that, although CF genotype affects CFTR function, it is not the only determinant. The influence of genes outside the CF locus [24] and environmental factors such as inflammation [25] have been advocated as possible factors that may modulate CFTR function. Moreover, in the airways, there is a complex network of various channels, including non-cAMP-dependent chloride channels [4]. These also influence the nasal PD and might in part explain the discrepancies between genotypes, the expected chloride transport, and the actual nasal PD measurements.

The findings, together with others [12], support the conclusion that cystic fibrosis patients with either normal nasal $\mathrm{Na}^{+}$transport or the ability to secrete chloride under stimulation are likely to have a better prognosis for respiratory function. This conclusion should be related to the recent finding that the concentration of salt in the airway surface liquid may influence not only the quality of mucociliary clearance but also its antibacterial property [26], two factors known to influence greatly respiratory function and prognosis. The present results are based on differences between groups of patients and care is needed in extrapolating these conclusions to a single individual. However, the results suggest that measurement of basal nasal potential difference, which can easily be carried out as a routine examination may be one of several factors that could help to predict the outcome of respiratory disease in cystic fibrosis. A normal nasal potential difference in a cystic fibrosis patient, even with a severe genotype, may indicate a less severe outcome of the respiratory disease than expected.

Acknowledgements: The authors would like to thank M.-F. Combalot, I. Eyot, M. Lachaux, M. Morin, J. Siret and S. Rém-eur for technical assistance.

\section{References}

1. Riordan JR, Rommens JM, Kerem B-S, et al. Identification of the cystic fibrosis gene: cloning and characterization of complementary DNA. Science 1989; 245: 1066-1073.

2. Zielenski J, Tsui L-C. Cystic fibrosis: genotypic and phenotypic variations. Annu Rev Genet 1995; 29: 777-807.

3. Frizzell RA. Functions of the cystic fibrosis transmembrane conductance regulator protein. Am J Respir Crit Care Med 1995; 151: S54-S58.

4. Boucher RC. Human airway ion transport, part I. Am J Respir Crit Care Med 1994; 150: 271-281.

5. Knowles MR, Carlson JL, Collier AM, Gatzy JT, Boucher RC. Measurements of nasal transepithelial electric potential differences in normal human subjects in vivo. Am Rev Respir Dis 1981; 124: 484-490. 
6. Knowles M, Gatzy J, Boucher R. Increased bioelectric potential difference across respiratory epithelia in cystic fibrosis. N Engl J Med 1981; 305: 1489-1495.

7. Alton EWFW, Currie D, Logan-Sinclair R, Warner JO, Hodson ME, Geddes DM. Nasal potential difference: a clinical diagnostic test for cystic fibrosis. Eur Respir $J$ 1990; 3: 922-926.

8. Welsh MJ, Smith AE. Molecular mechanisms of CFTR chloride channel dysfunction in cystic fibrosis. Cell 1993; 73: 1251-1254.

9. Hofmann T, Böhmer O, Hüls G, et al. Conventional and modified nasal potential-difference measurement in cystic fibrosis. Am J Respir Crit Care Med 1997; 155: 19081913.

10. Walker LC, Venglarik CJ, Aubin G, et al. Relationship between airway ion transport and a mild pulmonary disease mutation in CFTR. Am J Respir Crit Care Med 1997; 155: 1684-1689.

11. Durie PR, Ellis L, Corey M, et al. Nasal transepithelial potential difference in patients with defined CFTR gene mutations (Abstract). Pediatr Pulmonol 1995; Suppl. 12: 202.

12. Ho LP, Samways JM, Porteous DJ, et al. Correlation between nasal potential difference measurements, genotype and clinical condition in patients with cystic fibrosis. Eur Respir J 1997; 10: 2018-2022.

13. Mialon P, Charfi R, Regnard J, Lockhart A, Dinh-Xuan AT. Locally deposited but not inhaled frusemide reduces nasal potential difference in healthy subjects. Eur J Clin Pharmacol 1993; 45: 347-351.

14. Bienvenu T, Cazeneuve C, Kaplan JC, Beldjord C. Mutation heterogeneity of cystic fibrosis in France: screening by denaturing gradient gel electrophoresis using psoralen-modified oligonucleotide. Hum Mutat 1995; 6: 2329.

15. Fanen P, Ghanem N, Vidaud M, et al. Molecular characterization of cystic fibrosis: 16 novel mutations identified by analysis of the whole cystic fibrosis conductance transmembrane regulator (CFTR) coding regions and splice site junctions. Genomics 1992; 13: 770-776.

16. Sanger F, Milken S, Coulson AR. DNA sequencing with chain terminating inhibitors. Proc Natl Acad Sci USA 1977; 74: 5463-5467.

17. Highsmith WE, Burch LH, Zhou Z, et al. A novel mutation in the cystic fibrosis gene in patients with pulmonary disease but normal sweat chloride concentrations. $N$ Engl J Med 1994; 331: 974-980.

18. Chillòn M, Dörk T, Casals T, et al. A novel donor splice site in intron 11 of the CFTR gene, created by mutation $1811+1.6 \mathrm{~kb} \mathrm{~A} \rightarrow \mathrm{G}$, produces a new exon: high frequency in Spanish cystic fibrosis chromosomes and association with severe phenotype. Am J Hum Genet 1995; 56: 623629.

19. Hubert D, Bienvenu T, Desmazes-Dufeu N, et al. Genotype-phenotype relationships in a cohort of adult cystic fibrosis patients. Eur Respir J 1996; 9: 2207-2214.

20. Knowles MR, Paradiso AM, Boucher RC. In vivo nasal potential difference: techniques and protocols for assessing efficacy of gene transfer in cystic fibrosis. Hum Gene Ther 1995; 6: 445-455.

21. Wilson R, Alton E, Rutman A, et al. Upper respiratory tract viral infection and mucociliary clearance. Eur $J$ Respir Dis 1987; 70: 272-279.

22. Knowles MR, Stutts MJ, Spock A, Fischer N, Gatzy JT, Boucher RC. Abnormal ion permeation through cystic fibrosis respiratory epithelium. Science 1983; 221: 1067-1070.

23. Veeze HJ, Halley DJJ, Bijman J, de Jongste JC, de Jonge HR, Sinaasappel M. Determinants of mild clinical symptoms in cystic fibrosis patients. J Clin Invest 1994; 93: 461-466.

24. Santis G, Osborne L, Knight RA, Hodson ME. Linked marker haplotypes and the $\Delta$ F508 mutation in adults with mild pulmonary disease and cystic fibrosis. Lancet 1990; 335: 1426-1429.

25. Dupuit F, Kälin N, Brézillon S, Hinnrasky J, Tümmler B, Puchelle E. CFTR and differentiation markers expression in non-CF and $\triangle \mathrm{F} 508$ homozygous CF nasal epithelium. J Clin Invest 1995; 96: 1601-1611.

26. Smith JJ, Travis SM, Greenberg EP, Welsh MJ. Cystic fibrosis airway epithelia fail to kill bacteria because of abnormal airway surface fluid. Cell 1996; 85: 229-236. 